\title{
Enhancing the Therapeutic Efficacy of 2-Deoxyglucose in Breast Cancer Cells Using Cell-cycle Synchronization
}

\author{
SU JIN LEE ${ }^{1}$, BOK-NAM PARK ${ }^{1}$, JUNG HYUN ROH ${ }^{1}$, YOUNG-SIL AN ${ }^{1}$, HOON HUR ${ }^{2}$ and JOON-KEE YOON ${ }^{1}$ \\ Departments of ${ }^{1}$ Nuclear Medicine and Molecular Imaging, and \\ ${ }^{2}$ Surgery, Ajou University School of Medicine, Suwon, Republic of Korea
}

\begin{abstract}
Aim: We assessed the effect of cell-cycle synchronization using the T-type calcium channel inhibitor mibefradil on the anticancer effects of 2-deoxy-D-glucose (2$D G)$ and glucose metabolism in breast cancer cells. Materials and Methods: MDA-MB-231 cells were treated with mibefradil, followed by 2-DG with/without paclitaxel, then cells were assessed for viability. Glucose metabolism was evaluated by ${ }^{3} \mathrm{H}-2-D G$ uptake, lactate concentration, and membrane glucose transporter 1 expression after mibefradil treatment. Results: Viability was significantly lower in cells receiving the combination therapy of mibefradil and 2-DG relative to 2-DG treatment alone; addition of paclitaxel to the combination therapy further reduced the viability of breast cancer cells. Withdrawal of mibefradil resulted in a significant increase in cellular ${ }^{3} \mathrm{H}$ 2-DG uptake uptake, a slight accumulation of lactate, and increased membrane glucose transporter 1 expression. Conclusion: Mibefradil-induced cell-cycle synchronization enhanced the anticancer activity of 2-DG in breast cancer cells due to an increase in cellular glucose metabolism.
\end{abstract}

Biochemical differences in cellular metabolism between cancer and normal cells represent promising targets for cancer treatment (1). Many types of cancers demonstrate an increase in glycolysis followed by anaerobic metabolism, even under high oxygen conditions, a phenomenon known as the Warburg effect (2). This sharp distinction between cancer and normal cells provides a biochemical basis for preferentially killing malignant cells by inhibiting glycolysis

Correspondence to: Joon-Kee Yoon, MD, Ph.D., Department of Nuclear Medicine and Molecular Imaging, Ajou University School of Medicine, 164, World cup-ro, Yeongtong-gu, Suwon 443-380, Republic of Korea. Tel: +82 312194303, Fax: +82 312195950, email: jkyoon3@ajou.ac.kr

Key Words: Mibefradil, cell cycle, deoxyglucose, breast neoplasms, calcium channels.
One of the most frequently used inhibitors of glucose metabolism is 2-deoxy-D-glucose (2-DG). 2-DG is phosphorylated by hexokinase, resulting in a depletion of intracellular ATP and induction of autophagy (3). However, as high concentrations of 2-DG are needed to inhibit the glycolytic metabolism of cancer cells (4), approaches that can enhance the efficacy of 2-DG are needed. Several recent studies have reported enhanced anticancer effects of 2-DG in combination with other drugs in prostate and breast cancer (5-7).

To date, few studies have examined the association between glucose metabolism and the cell cycle in cancer cells. In non-Hodgkin's lymphoma, high 2-[ $\left.{ }^{18} \mathrm{~F}\right]$-fluoro-2deoxy-D-glucose (FDG) accumulation was shown to be related to an increased proportion of cells in $\mathrm{S}$ phase (8). We, therefore, hypothesized that $\mathrm{S}$-phase induction after cellcycle synchronization at the $\mathrm{G}_{1} / \mathrm{S}$ checkpoint may augment the therapeutic effect of 2-DG (Figure 1A). Among cellcycle modulators, T-type calcium channel inhibitors represent promising candidates, as these channels are commonly expressed in many types of cancer. Furthermore, T-type calcium channel-specific blockers have been shown to inhibit cancer cell proliferation, in part, by restricting the cell cycle at the $\mathrm{G}_{1} / \mathrm{S}$ interphase $(9,10)$.

Breast cancer is the second most commonly diagnosed cancer worldwide (1.38 million cases per year, 10.9\%) (11). Among breast cancer cell lines, MCF-7 and MDA-MB-231 cells are known to express T-type calcium channels in nonconfluent culture (12). While mibefradil, a selective T-type calcium channel inhibitor, has been shown to inhibit MCF-7 cell growth through the induction of necrosis (13), neither the effect of mibefradil on triple-negative breast cancer cells nor the effect of combination therapy with mibefradil and 2DG in cancer cells has been studied. In this study, we therefore sought to assess the anticancer effects of 2-DG when used in combination with the T-type calcium channel inhibitor mibefradil on breast cancer cells, and further investigated how cell-cycle synchronization using mibefradil affects glucose uptake. 


\section{Materials and Methods}

Cell culture. The MDA-MB-231 breast cancer cell line (14) was obtained from the Korean Cell Line Bank (KCLB No. 30026; Seoul, Korea). Cells were cultured as monolayers in RPMI-1640 medium (HyClone, GE Healthcare Life Sciences, Logan, UT, USA) supplemented with $10 \%$ fetal bovine serum (HyClone) and $1 \%$ penicillin/streptomycin (Gibco, Thermo Fisher Scientific, Waltham, MA, USA), and maintained under full humidity at $37^{\circ} \mathrm{C}$ and $5 \%$ $\mathrm{CO}_{2}$. All experiments were performed in triplicate and the results were reproduced at least twice. The experimental protocol is shown in Figure 1B.

Cell-cycle analysis. MDA-MB-231 cells were seeded into 6-well plates and cultured overnight. For the treatment group, $10 \mu \mathrm{M}$ or 20 $\mu \mathrm{M}$ mibefradil (Sigma-Aldrich, St. Louis, MO, USA) was added, and cells were incubated for $24 \mathrm{~h}$. Cells were then collected by trypsinization at 0,20 and $24 \mathrm{~h}$ after removing mibefradil, rinsed twice in $5 \mathrm{ml}$ of $0.1 \%$ bovine serum albumin/phosphate-buffered saline (PBS), and fixed with $3 \mathrm{ml}$ cold $70 \%$ ethanol. Samples were then stored at $-20^{\circ} \mathrm{C}$ until needed. On the day of analysis, samples were transferred to flow cytometry tubes and washed twice with PBS. After removing the supernatant by centrifugation, the cell pellet was resuspended in $3 \mathrm{ml}$ PBS containing $0.1 \%$ Triton X-100, 10 $\mu \mathrm{g} / \mathrm{ml}$ propidium iodide and $100 \mu \mathrm{g} / \mathrm{ml} \mathrm{RNase}$, and then incubated at room temperature for $30 \mathrm{~min}$. Cell suspensions were then analyzed by flow cytometry (BD Bioscience, San Jose, CA, USA) with Flowjo software (ver. 7.6 Flowjo; LLC, Ashland, OR, USA).

Sulforhodamine-B (SRB) assay. Cells were categorized into control, mibefradil alone, 2-DG alone, and combination therapy (mibefradil followed by 2-DG) treatment groups. Cells were seeded into 96-well plates and cultured overnight. For mibefradil treatment and combination therapy groups, cells were first incubated with $10 \mu \mathrm{M}$ mibefradil for $24 \mathrm{~h}$. The cell medium was then replaced with fresh medium (for control and mibefradil treatment groups) or medium containing 1.0 or $2.5 \mathrm{mM} 2$-DG (for 2-DG treatment group and combination therapy groups) and cells were incubated for a further $48 \mathrm{~h}$. For the SRB assay, cells were fixed for $1 \mathrm{~h}$ at $4^{\circ} \mathrm{C}$ in $3.3 \%$ $(\mathrm{w} / \mathrm{v})$ trichloroacetic acid (Sigma-Aldrich). After removing fixation solution from the plates, cells were incubated with $100 \mu \mathrm{l}$ of $0.057 \%$ (w/v) SRB (Sigma-Aldrich) at room temperature for $10 \mathrm{~min}$. Cells were then rinsed four times with $1 \%(\mathrm{v} / \mathrm{v})$ acetic acid and dried. Stained cells were dissolved in $100 \mu 10 \mathrm{mM}$ Tris base ( $\mathrm{pH} 10.5)$ for $10 \mathrm{~min}$ with shaking. Finally, absorbance at $490 \mathrm{~nm}$ was measured on a microplate reader (VMax; Molecular Devices, Sunnyvale, CA, USA).

After confirming the effect of mibefradil on 2-DG treatment in breast cancer cells, we investigated whether a chemotherapeutic agent could enhance the therapeutic effect of 2-DG and cell-cycle synchronization combination therapy. For this purpose, cells were treated with $10 \mathrm{nM}$ paclitaxel (Sigma-Aldrich) for two consecutive days after pretreatment with mibefradil for $24 \mathrm{~h}$, and the SRB assay was performed.

${ }^{3} H-2-D G$ Uptake measurement. Cells were seeded into 12-well and cultured overnight. After incubation with $10 \mu \mathrm{M}$ mibefradil for $24 \mathrm{~h}$, cells were washed with warm PBS, and then incubated in lowglucose culture media containing $18.5 \mathrm{kBq}{ }^{3} \mathrm{H}-2-\mathrm{DG}$ for up to $48 \mathrm{~h}$. After rapid washing with cold PBS twice, cells were lysed with

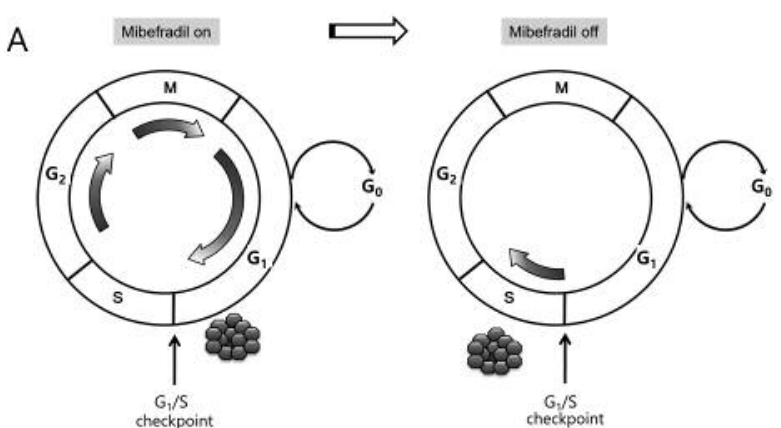

B

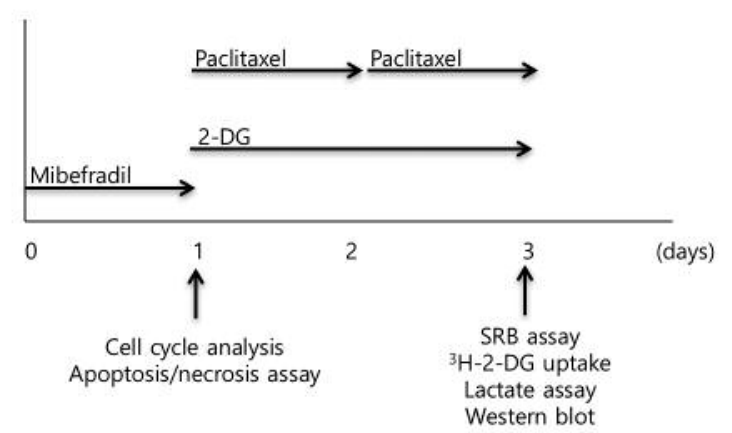

Figure 1. Schematic representations of an induction of progression to $S$ phase by cell-cycle synchronization with T-type calcium channel inhibitor, mibefradil (A) and the experimental protocol (B). 2-DG, 2-Deoxy-Dglucose; SRB, sulforhodamine- $B ;{ }^{3} H-D G,{ }^{3} H$-2-deoxy-D-glucose.

$0.1 \mathrm{~N} \mathrm{NaOH}$. Radioactivity was measured using a liquid scintillation counter and normalized to protein content using Pierce-660 (Thermo Fisher Scientific).

Lactate production assay. Cells were seeded into 12-well plates and cultured overnight. Culture medium $(50 \mu \mathrm{l})$ was collected $48 \mathrm{~h}$ after $10 \mu \mathrm{M}$ mibefradil treatment, and lactate concentration was measured using an L-Lactate Assay Kit (Eton Bioscience, San Diego, CA, USA) according to the manufacturer's instructions.

Apoptosis and necrosis assays. Apoptosis and necrosis assays for mibefradil-treated cells were performed using a annexin Vfluorescein isothiocyanate Apoptosis Detection Kit (BD Pharmingen, BD Bioscience) and a flow cytometer according to the manufacturer's guidelines. Following treatment, cells were detached with trypsin, washed twice with cold PBS, and resuspended in binding buffer. For each tube, $5 \mu$ l annexin V-fluorescein isothiocyanate and $5 \mu \mathrm{l}$ propidium iodide were added, and the mixture was incubated for $15 \mathrm{~min}$ at room temperature in the dark. Within $1 \mathrm{~h}$ of incubation, cells were analyzed by flow cytometry.

Immunoblotting for plasma membrane glucose transporter 1 (GLUT1). Total membranes of breast cells were extracted using a Minute Plasma Membrane Isolation Kit (Invent Biotechnologies, Plymouth, MN, USA). Protein was transferred to lanes of a hydrobond enhanced chemiluminescent nitrocellulose membrane 
A

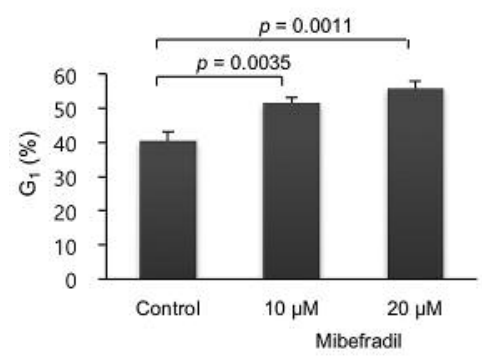

B

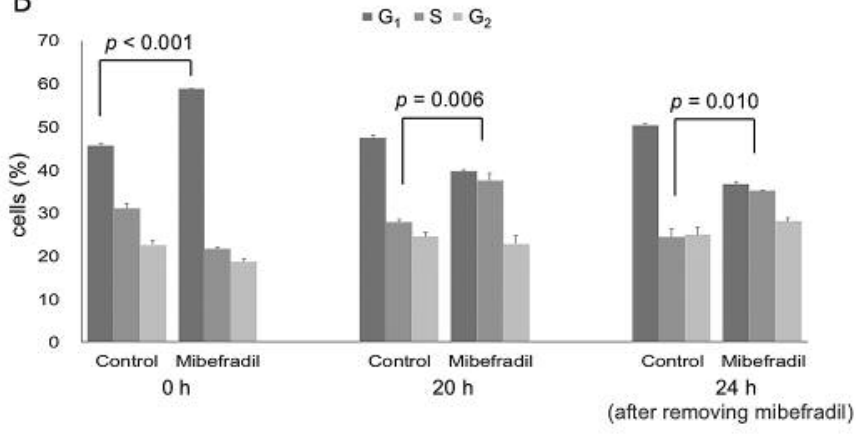

Figure 2. A: Cell-cycle arrest in MDA-MB-231 cells. Cell cycle was analyzed by flow cytometry after 10 or $20 \mu M$ calcium channel inhibitor, mibefradil. B: Sequential cell cycle changes after mibefradil treatment of MDA-MB-231 cells. Cells were treated with $10 \mu M$ mibefradil for 24 h, then the cell cycle distribution was analyzed by flow cytometry for $24 \mathrm{~h}$ after removing mibefradil. Data are the mean standard deviation.

and incubated overnight at $4^{\circ} \mathrm{C}$ with a monoclonal antibody to human GLUT1 (1:1,000 dilution; Abcam, Cambridge, MA, USA). Immunoreactive protein was visualized following a 1-h incubation with a horseradish peroxidase-conjugated antibody to mouse IgG (1:10,000 dilution; Thermo Fisher Scientific) and exposure on highperformance chemiluminescence film.

Statistical analysis. Results are expressed as the mean \pm standard deviation. Comparisons between groups were evaluated using the Student's $t$-test, with $p$-values of less than 0.05 considered significant.

\section{Results}

$G_{1}$ arrest after mibefradil treatment. Mibefradil treatment successfully induced cell-cycle arrest at the $G_{1}$ phase. The proportion of MDA-MB-231 cells in the $\mathrm{G}_{1}$ phase following treatment with either 10 or $20 \mu \mathrm{M}$ mibefradil was significantly higher than that of the controls $(p<0.05$; Figure $2 A)$. This increase in $\mathrm{G}_{1}$ phase cells was accompanied by a significant decrease in the proportion in the $S$ phase $(p<0.05$; Figure $2 \mathrm{~B}$ ). The proportion of cells in the $\mathrm{G}_{2}-\mathrm{M}$ phase was not significantly different between control and treated cells.

The sequential change of each cell-cycle fraction was measured for $24 \mathrm{~h}$ after the cessation of $24 \mathrm{~h}$ treatment with $10 \mu \mathrm{M}$ mibefradil (Figure $2 \mathrm{~B}$ ). The $\mathrm{G}_{1}$-phase fraction of treated cells was higher than that of the control $(p<0.001)$ immediately after removing mibefradil, however, it decreased over time and was lower than that of control at 24 $\mathrm{h}$ after removal of the drug $(p<0.001)$. Conversely, the $\mathrm{S}$ phase fraction was initially lower in treated than in control cells $(p=0.002)$, whereas the converse was true at $20 \mathrm{~h}$ $(p=0.006)$ and $24 \mathrm{~h}(p=0.010)$ after removing the drug.

Therapeutic efficacy of cell-cycle synchronization on 2-DG treatment. Both 1.0 and $2.5 \mathrm{mM} 2-\mathrm{DG}$ alone for $48 \mathrm{~h}$ treatment significantly reduced the number of viable cells
( $p<0.05$; Figure 3A). Pretreatment with $10 \mu \mathrm{M}$ mibefradil further reduced the viability of cells for both $1.0 \mathrm{mM} 2-\mathrm{DG}$ $(p=0.0377)$ and $2.5 \mathrm{mM} 2-\mathrm{DG}$ treatments $(p=0.0001)$ compared with treatment with 2-DG alone. Cell viability also significantly decreased in the presence of $10 \mu \mathrm{M}$ mibefradil alone due to the inhibition of growth brought about by cellcycle arrest (reduction of $\sim 20 \% ; p=0.032$ ). No significant difference in viability was seen between cells treated with $1.0 \mathrm{mM}$ and $2.5 \mathrm{mM} 2-\mathrm{DG}(\sim 3 \% ; p=0.3803)$. However, after combination with mibefradil, this difference increased to $9.8 \%$ and approached statistical significance $(p=0.0601)$.

Addition of $10 \mathrm{nM}$ paclitaxel enhanced the therapeutic efficacy of the combination therapy with $10 \mu \mathrm{M}$ mibefradil and $1.0 \mathrm{mM}$ 2-DG synergistically. The viability of MDAMB-231 cells after treatment with all three drugs was only $15.8 \% \pm 4.6 \%$ of control, significantly lower than that of the mibefradil and 2-DG combination therapy (reduced by $\sim 75 \%, p=0.0001$; Figure 3B).

Glucose metabolism after cell-cycle synchronization by mibefradil. In order to evaluate the effect of cell-cycle synchronization on glucose metabolism in breast cancer cells, ${ }^{3} \mathrm{H}$-2-DG uptake, lactate concentration, and western blot analysis for GLUT1 were performed. Withdrawal of mibefradil resulted in a significant increase in cellular ${ }^{3} \mathrm{H}-$ 2-DG uptake at $48 \mathrm{~h}$ (by $\sim 2$-fold that of the control, $p=0.0008$; Figure 4A), as well as slightly reducing uptake at $24 \mathrm{~h}$. Lactate concentration in the culture medium also slightly increased at $48 \mathrm{~h}$ after mibefradil withdrawal compared to the control ( $p=0.0371$; Figure 4B). Western blot analysis revealed an increase in membrane expression of GLUT1 in treated cells relative to control cells (Figure 4C). Taken together, these results indicate that S-phase induction after cell-cycle synchronization is associated with increased glycolysis. 

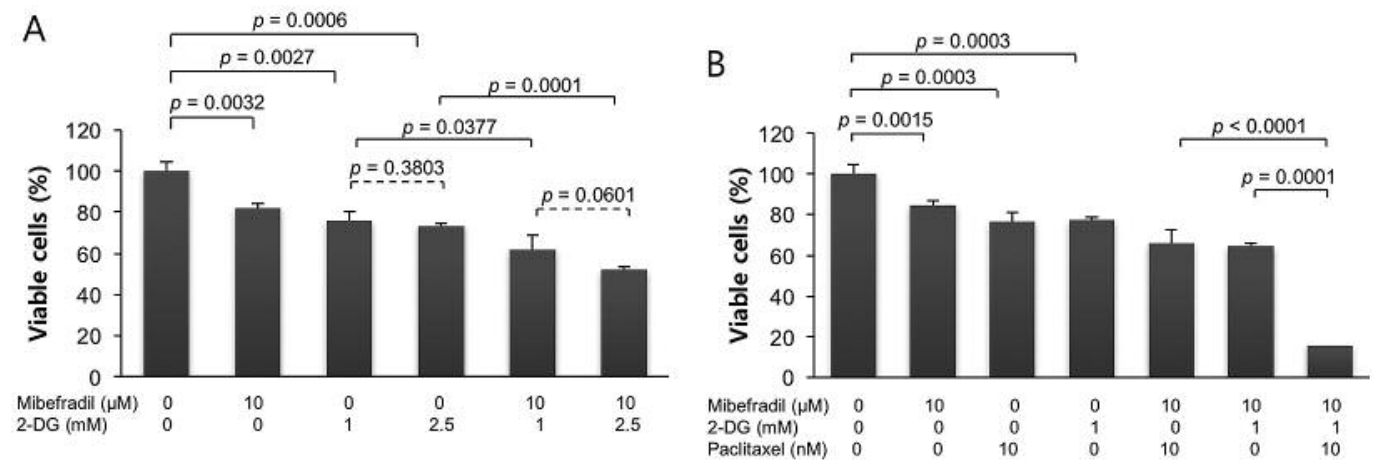

Figure 3. Therapeutic efficacies of the combination therapy with mibefradil $(10 \mu M)$ and 2-deoxy-D-glucose (2-DG; 1 or $2.5 \mathrm{mM})(\mathrm{A})$ and the triple combination therapy with mibefradil $(10 \mu \mathrm{M}), 2-D G(1 \mathrm{mM})$ and paclitaxel $(10 \mathrm{nM})(\mathrm{B})$ in MDA-MB-231 cells. Cells were treated with mibefradil for $24 \mathrm{~h}$, followed by 2-DG with/without paclitaxel for $48 \mathrm{~h}$. Data are the mean \pm standard deviation.
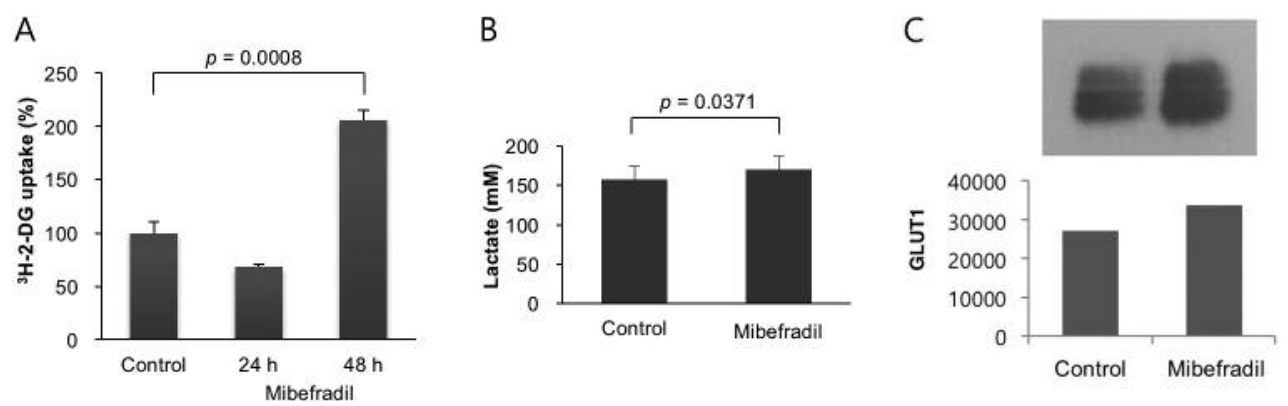

Figure 4. Evaluation of glucose metabolism in MDA-MB-231 cells. Cells were treated with $10 \mu \mathrm{M}$ mibefradil for $24 \mathrm{~h}$, then ${ }^{3} \mathrm{H}$-2-deoxy-D-glucose $\left({ }^{3} \mathrm{H}-2-D G\right)$ uptake at $24 \mathrm{~h}$ and $48 \mathrm{~h}$ after mibefradil withdrawal $(A)$, lactate concentration $(B)$, and relative expression of glucose transporter 1 (GLUT1) by western blot analysis $(C)$ were measured at $48 \mathrm{~h}$ after mibefradil withdrawal. Data are the mean \pm standard deviation.

Apoptosis and necrosis after cell-cycle synchronization by mibefradil. Flow cytometry revealed no significant difference in apoptotic and necrotic fractions between control $(3.6 \% \pm 1.3 \%$ and $10.1 \% \pm 4.5 \%$, respectively) and mibefradil treatment groups $(3.4 \% \pm 0.5 \%$ and $12.6 \% \pm 2.7 \%$, respectively, all $p>0.05$, Figure 5). These observations suggest that cell cycle synchronization by $10 \mu \mathrm{M}$ mibefradil did not induce apoptosis or necrosis in MDA-MB-231 cells.

\section{Discussion}

The data presented herein show that mibefradil significantly enhanced the therapeutic effect of 2-DG by exploiting the metabolic shift in glycolysis after cell-cycle synchronization of breast cancer cells. Moreover, this combination therapy exhibited further synergistic effects when used in combination with a conventional chemotherapeutic drug, paclitaxel. To the best of our knowledge, this study represents the first investigation examining the use of combination therapy based on the association between the cell cycle and cellular glucose metabolism in cancer.

A variety of cell-cycle modulators have been investigated for their potential anticancer efficacy due to the importance of the cell cycle in cancer pathogenesis (15). Among these, mibefradil, which was first developed as an anti-hypertensive drug only to be withdrawn from the market due to its serious drug-drug interaction with $\beta$-blockers $(16,17)$, was recently revisited for its use as an anticancer treatment. Recent investigations have revealed that mibefradil exerts an anticancer effect in several kinds of cancer. As a single agent, mibefradil suppressed the proliferation of astrocytoma, neuroblastoma and ovarian cancer cells $(18,19)$, while an interlaced approach combining mibefradil with temozolomide demonstrated a synergistic effect, reaching remission in a glioblastoma model, although mibefradil alone also significantly delayed tumor growth (20). Likewise, mibefradil significantly reduced tumor volume in a glioma model when used before or after radiosurgery (21). In the present study, 


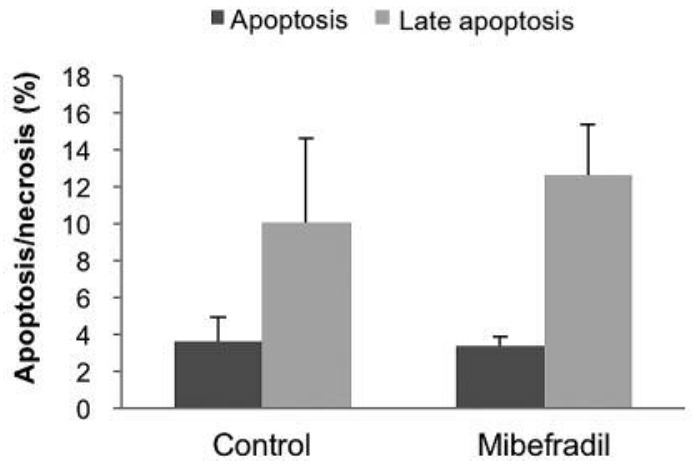

Figure 5. Apoptosis and necrosis of MDA-MB-231 cells after cell-cycle synchronization. Cells were treated with $10 \mu \mathrm{M}$ mibefradil for $24 \mathrm{~h}$ and flow cytometry was performed after propidium iodide and annexin $V$ fluorescein isothiocyanate staining. Treatment did not significantly affect apoptosis or necrosis ( $p=0.7510$ and 0.4535 , respectively). Data are the mean \pm standard deviation.

we also found that mibefradil not only inhibited cell proliferation, but also enhanced the therapeutic effect of 2DG in MDA-MB-231 cells.

Although the synergistic effect observed in the present study was similar to those of the previous studies, the mechanism of synergy was quite different. In our in vitro study, the S-phase fraction decreased immediately after mibefradil treatment (Figure 2), with a transient decrease in cellular ${ }^{3} \mathrm{H}-2-\mathrm{DG}$ uptake evident within the first $24 \mathrm{~h}$ after mibefradil withdrawal, followed by a significant increase in ${ }^{3} \mathrm{H}-2-\mathrm{DG}$ uptake at $48 \mathrm{~h}$. This pattern is indicative of an increase in cellular glucose uptake induced by S-phase propagation, and is the key mechanism driving the synergistic effect between mibefradil and 2-DG. These results are consistent with previous observations by Lapela et al. (8), in which they used positron-emission tomography to demonstrate a significant association between high ${ }^{18} \mathrm{~F}$-FDG accumulation and a high percentage of cells in the $S$ phase in deparaffinized tissues collected from untreated patients with non-Hodgkin lymphoma. Although the situation is different, our results are broadly consistent with theirs, in that the percentage of cells in the $\mathrm{S}$ phase was closely related to glucose utilization.

Having established a relationship between cell-cycle stage and 2-DG activity, we next investigated the effect of S-phase propagation on ${ }^{3} \mathrm{H}-2-\mathrm{DG}$ uptake with respect to glucose metabolism. Western blot analysis for GLUT1 (22), revealed that membranous GLUT1 expression was increased after mibefradil withdrawal. In addition, lactate production, as measured in the culture medium, was also increased. These results indicate that augmented glycolytic flux after cessation of cell-cycle synchronization is the major force driving increased uptake of 2-DG by MDA-MB-231 cells.
Cell-cycle synchronization using mibefradil may increase apoptosis or necrosis of cancer cells. In an in vitro study of C6 glioma cells, 2, 5 and $7 \mu \mathrm{M}$ mibefradil increased apoptosis in a dose-dependent fashion (21). Mibefradil treatment was also shown to increase the necrotic fraction by $20 \%$ in MCF-7 breast cancer cells, while another T-type calcium channel inhibitor, pimozide, significantly elevated the apoptotic fraction (13). Here, we failed to observe any increase in apoptosis or necrosis in MDA-MB-231 cells following treatment with $10 \mu \mathrm{M}$ mibefradil. Taken together, these results suggest that the effect of mibefradil on cell death is dependent on both cell type and dosage.

Combination therapy using 2-DG along with other chemotherapeutic agents has been shown to exhibit synergistic activity in many types of cancer (23-25). Our result using the combination therapy of 2-DG and paclitaxel is consistent with these observations. Furthermore, our triple combination therapy, consisting of mibefradil followed by 2 DG and paclitaxel, exerted a dramatic anticancer effect ( $15.8 \%$, relative to controls). These findings suggest that mibefradil has the potential to enhance the therapeutic efficacy and reduce the side-effects of conventional therapy by virtue of reducing therapeutic doses.

One limitation of this study is that we were unable to correlate each cell-cycle phase directly to ${ }^{3} \mathrm{H}-2-\mathrm{DG}$ uptake. From a technical standpoint, it is difficult to separate individual cells based upon their cell-cycle phase after incubation with ${ }^{3} \mathrm{H}-2-\mathrm{DG}$, and to observe cell-cycle phase and ${ }^{3} \mathrm{H}-2-\mathrm{DG}$ uptake simultaneously. Further experimental evaluation is required to confirm the correlation between ${ }^{3} \mathrm{H}-$ 2-DG uptake and S phase in cancer cells. Another limitation is that our analyses were performed in vitro using only one breast cancer cell line. Further studies with other malignant tumor cells that express T-type calcium channels, as well and small-animal tumor models, will be needed to fully evaluate the anticancer effect of this combination therapy.

\section{Conclusion}

Cell-cycle synchronization by mibefradil significantly increased the therapeutic effect of 2-DG due to enhanced glycolysis by breast cancer cells. Further addition of paclitaxel to combination therapy revealed a dramatic anticancer effect. These results may warrant further preclinical and clinical studies to assess the therapeutic effect of combination therapy using T-type calcium channel inhibitors and 2-DG.

\section{Conflicts of Interest}

None of the Authors has any conflict of interest in regard to this study. 


\section{Acknowledgements}

This work was supported by the new faculty research fund of Ajou University School of Medicine and Basic Science Research Program through the National Research Foundation of Korea (NRF) funded by the Ministry of Education, Science and Technology (NRF2013R1A1A1061661). J-K (Yoon) would like to express his sincere thanks to Professor Sanjiv Sam Gambhir at Stanford University. This study is based on previous experience and learning at his laboratory.

\section{References}

1 Kroemer G and Pouyssegur J: Tumor cell metabolism: cancer's Achilles' heel. Cancer Cell 13: 472-482, 2008.

2 Brown J: Effects of 2-deoxyglucose on carbohydrate metablism: review of the literature and studies in the rat. Metabolism 11: 1098-1112, 1962.

3 Pelicano H, Martin DS, Xu RH and Huang P: Glycolysis inhibition for anticancer treatment. Oncogene 25: 4633-4646, 2006.

4 Wu H, Zhu H, Liu DX, Niu TK, Ren X, Patel R, Hait WN and Yang JM: Silencing of elongation factor-2 kinase potentiates the effect of 2-deoxy-D-glucose against human glioma cells through blunting of autophagy. Cancer Res 69: 2453-2460, 2009.

5 Ben Sahra I, Laurent K, Giuliano S, Larbret F, Ponzio G, Gounon P, Le Marchand-Brustel Y, Giorgetti-Peraldi S, Cormont M, Bertolotto C, Deckert M, Auberger P, Tanti JF and Bost F: Targeting cancer cell metabolism: the combination of metformin and 2-deoxyglucose induces p53-dependent apoptosis in prostate cancer cells. Cancer Res 70: 2465-2475, 2010.

6 Cheng G, Zielonka J, Dranka BP, McAllister D, Mackinnon AC, Jr., Joseph J and Kalyanaraman B: Mitochondria-targeted drugs synergize with 2-deoxyglucose to trigger breast cancer cell death. Cancer Res 72: 2634-2644, 2012.

7 Cao J, Cui S, Li S, Du C, Tian J, Wan S, Qian Z, Gu Y, Chen WR and Wang G: Targeted cancer therapy with a 2deoxyglucose-based adriamycin complex. Cancer Res 73: 13621373, 2013.

8 Lapela M, Leskinen S, Minn HR, Lindholm P, Klemi PJ, Soderstrom KO, Bergman J, Haaparanta M, Ruotsalainen U, Solin $\mathrm{O}$ and Joensuu $\mathrm{H}$ : Increased glucose metabolism in untreated non-Hodgkin's lymphoma: a study with positron emission tomography and fluorine-18-fluorodeoxyglucose. Blood 86: 3522-3527, 1995.

9 Gray LS and Macdonald TL: The pharmacology and regulation of T-type calcium channels: new opportunities for unique therapeutics for cancer. Cell Calcium 40: 115-120, 2006.

10 Taylor JT, Zeng XB, Pottle JE, Lee K, Wang AR, Yi SG, Scruggs JA, Sikka SS and Li M: Calcium signaling and T-type calcium channels in cancer cell cycling. World J Gastroenterol 14: 4984-4991, 2008.

11 Ferlay J, Shin HR, Bray F, Forman D, Mathers C and Parkin DM: Estimates of worldwide burden of cancer in 2008: GLOBOCAN 2008. Int J Cancer 127: 2893-2917, 2010.
12 Taylor JT, Huang L, Pottle JE, Liu K, Yang Y, Zeng X, Keyser BM, Agrawal KC, Hansen JB and Li M: Selective blockade of T-type $\mathrm{Ca}^{2+}$ channels suppresses human breast cancer cell proliferation. Cancer Lett 267: 116-124, 2008.

13 Bertolesi GE, Shi C, Elbaum L, Jollimore C, Rozenberg G, Barnes S and Kelly ME: The $\mathrm{Ca}(2+)$ channel antagonists mibefradil and pimozide inhibit cell growth via different cytotoxic mechanisms. Mol Pharmacol 62: 210-219, 2002.

14 Cailleau R, Young R, Olive M and Reeves WJ Jr.: Breast tumor cell lines from pleural effusions. J Natl Cancer Inst 53: 661-674, 1974.

15 Deep G and Agarwal R: New combination therapies with cellcycle agents. Curr Opin Investig Drugs 9: 591-604, 2008.

16 Po AL and Zhang WY: What lessons can be learnt from withdrawal of mibefradil from the market? Lancet 351: 18291830, 1998.

17 SoRelle R: Withdrawal of posicor from market. Circulation 98: 831-832, 1998.

18 Li W, Zhang SL, Wang N, Zhang BB and Li M: Blockade of Ttype $\mathrm{Ca}(2+)$ channels inhibits human ovarian cancer cell proliferation. Cancer Invest 29: 339-346, 2011.

19 Panner A, Cribbs LL, Zainelli GM, Origitano TC, Singh S and Wurster RD: Variation of T-type calcium channel protein expression affects cell division of cultured tumor cells. Cell Calcium 37: 105-119, 2005.

20 Keir ST, Friedman HS, Reardon DA, Bigner DD and Gray LA: Mibefradil, a novel therapy for glioblastoma multiforme: cellcycle synchronization and interlaced therapy in a murine model. J Neurooncol 111: 97-102, 2013.

21 Sheehan JP, Xu Z, Popp B, Kowalski L and Schlesinger D: Inhibition of glioblastoma and enhancement of survival via the use of mibefradil in conjunction with radiosurgery. J Neurosurg 118: 830-837, 2013.

22 Grover-McKay M, Walsh SA, Seftor EA, Thomas PA and Hendrix MJ: Role for glucose transporter 1 protein in human breast cancer. Pathol Oncol Res 4: 115-120, 1998.

23 Maschek G, Savaraj N, Priebe W, Braunschweiger P, Hamilton K, Tidmarsh GF, De Young LR and Lampidis TJ: 2-deoxy-Dglucose increases the efficacy of adriamycin and paclitaxel in human osteosarcoma and non-small cell lung cancers in vivo. Cancer Res 64: 31-34, 2004.

24 Simons AL, Ahmad IM, Mattson DM, Dornfeld KJ and Spitz DR: 2-Deoxy-D-glucose combined with cisplatin enhances cytotoxicity via metabolic oxidative stress in human head and neck cancer cells. Cancer Res 67: 3364-3370, 2007.

25 Chuang JH, Chou MH, Tai MH, Lin TK, Liou CW, Chen T, Hsu WM and Wang PW: 2-Deoxyglucose treatment complements the cisplatin- or BH3-only mimetic-induced suppression of neuroblastoma cell growth. Int J Biochem Cell Biol 45: 944-951, 2013.

Received August 22, 2016

Revised September 13, 2016

Accepted September 15, 2016 